\title{
TEMPI syndrome
}

INSERM

\section{Source}

INSERM. (1999). Orphanet: an online rare disease and orphan drug data base. TEMPI syndrome. ORPHA:284227

TEMPI syndrome is a rare multi-systemic disease characterized by the presence of Telang iectasias, Erythrocytosis with elevated erythropoietin levels, Monoclonal gammopathy, Perinephric-fluid collections, and Intrapulmonary shunting. 